\title{
Role of medicinal plants in the treatment of eumycetoma: A review
}

\author{
Shashank M. Patil ${ }^{1}$, S. Jagadeep Chandra ${ }^{2}$, M. K. Jayanthi ${ }^{3}$, Prithvi S. Shirahatti ${ }^{4}$, Ramith Ramu ${ }^{1 *}$ \\ ${ }^{1}$ Department of Biotechnology and Bioinformatics, Faculty of Life Sciences, JSS Academy of Higher Education and Research, Mysuru, India. \\ ${ }^{2}$ Department of Microbiology, Faculty of Life Sciences, JSS Academy of Higher Education and Research, Mysuru, India. \\ ${ }^{3}$ Department of Pharmacology, JSS Medical College, JSS Academy of Higher Education and Research, Mysuru, India. \\ ${ }^{4}$ Department of Biotechnology, Teresian College, Siddhartha Nagara, Mysuru, India.
}

\begin{tabular}{l}
\hline ARTICLE INFO \\
\hline Article history: \\
Received on: January 12, 2021 \\
Accepted on: March 27, 2021 \\
Available online: September 01, 2021
\end{tabular}

Key words:

Mycetoma, eumycetoma, NTDs, diagnosis, treatment, antifungal agents, phytotherapy.

\begin{abstract}
Mycetoma is a resultant infection of either fungi (eumycetoma) or bacteria (actinomycetoma). It is categorized under neglected tropical diseases, as it typically affects the economically backward communities of the endemic regions. The infection occurs with the invasion of etiological agents through the open wounds of the body. The cutaneous and subcutaneous tissue is characterized by the sinus formation and discharge. Primarily affecting the foot, it further spreads to other parts of the body. Eumycetoma has a worldwide distribution yet considered endemic, as it is restricted only to few countries. Diagnosis and treatment of the disease has been burdensome since poor response and unavailability of medical support in endemic regions. Microbiological and serological diagnostic methods have been unreliable except molecular diagnostics. Treatment with antifungal agents has given a mixed response, with only itraconazole being effective. These techniques are relatively expensive and cannot be afforded by people with weak economic background. In the context, it becomes essential to introduce phytotherapy to relieve the health and economic burden. Herein, we discuss few medicinal plants with profound antifungal activity towards eumycetoma. We highlight the possible course of actions that needs to be put forward to deliver the plant-based drugs to cure eumycetoma.
\end{abstract}

\section{INTRODUCTION}

Mycetoma refers to a chronic, inflammatory, granulomatous, nodular infection of cutaneous and subcutaneous tissue that is caused by either bacteria or fungi [1,2]. Based on the causative agents, it is further classified as eumycetoma (fungi) and actinomycetes (aerobic bacteria). Both the diseases share similar medical complexities and predominantly affect the feet, and rarely infect the other parts of the body $[3,4]$. Actinomycetes account for the $60 \%$ of the worldwide cases, whereas the rest is linked with the eumycetoma. In case of eumycetoma, $90 \%$ of the infections caused by the fungi including Madurella mycetomatis, Madurella grisea, Leptosphaeria senegalensis, and Pseudallescheria boydii. In addition, there are several other fungi reported with rare infections, which are depicted in Table $1[5,6]$. These fungi are suspected to enter the host through localized trauma such as

*Corresponding Author

Ramith Ramu, Department of Biotechnology and Bioinformatics, Faculty of Life Sciences, JSS Academy of Higher Education and Research, Mysuru, India.E-mail: ramithramu@jssuni.edu.in open wounds from woody plants and soil. This is followed by the progressive, painless formation of tumor projections on the feet in the subsequent time interval $[7,8]$.

The morphological and histological examinations reveal the formation of abscesses comprising large and compact masses of fungal filaments termed as grains. Through the draining sinuses, these grains comprising the etiological agent are discharged [9]. This is considered as a unique character of this disease. The tumors thus caused on the cutaneous and subcutaneous tissue are often putrefying [10]. Destruction of deep tissues including muscles, tendons, bones, and joints is also observed [11]. This may further lead into the loss of function, deformity, and occasionally to death. The disease usually affects young adults and is prevalent in males aged between 15 and 30 years. However, early detection and treatment could reduce the morbidity and augment the treatment outcomes [7,12].

The disease is believed to possess several adverse impacts with respect to medical, health, and socio-economical aspects. Inaccurate and deficient amount of data on epidemiological details is available, though few of the studies depict some of the countries 
Table 1: Fungal species causing eumycetoma

\begin{tabular}{|c|c|}
\hline Type of infection & Fungal species \\
\hline Most common & M. mycetomatis \\
\hline$>90 \%$ of the infection & M. mycetomatis, $M$. grisea, L. senegalensis, and P. boydii \\
\hline Rare infection & $\begin{array}{l}\text { Acremonium spp. (Acremonium falciforme, Acremonium kiliense, and Acremonium recifei), Aspergillus spp. (Aspergillus flavus, Aspergillus fumigatus, } \\
\text { and Aspergillus nidulans), Biatriospora mackinnonii, Cladophialophora spp. (Cladophialophora bantiana and C. mycetomatis), Cladosporium carrionii, } \\
\text { Cochliobolus lunatus, Curvularia geniculata, Cylindrocarpon cyanescens, E. jeanselmei, F. senegalensis, Fusarium spp. (F. chlamydosporum, Fusarium } \\
\text { falciforme, Fusarium moniliforme, Fusarium solani, and Fusarium subglutinans), Geotrichum candidum, Hormonema spp. Leptosphaeria tompkinsii, } \\
\text { M. romeroi, Microsporum spp. Neoscytalidium dimidiatum, Neotestudina rosatii, Paecilomyces lilacinus, Phialophora spp. (Phialophora jeanselmei } \\
\text { and Phialophora verrucosa), Pleurostomophora ochracea, Pyrenochaeta spp. (Pyrenochaeta mackinnonii and Pyrenochaeta romeroi), Rhinocladiella } \\
\text { atrovirens, S. boydii, T. grisea, Trichophyton spp. }\end{array}$ \\
\hline
\end{tabular}

Adapted from Verma and Jha [5], Zijlstra et al. [6].

as endemic [12]. For example, omnipresence of collective mycetoma is observed in the region between $30^{\circ} \mathrm{N}$ and $15^{\circ} \mathrm{N}$, that is known as "Mycetoma belt." Several countries fall in this region including Mexico, Venezuela, Argentina, Columbia, Senegal, Sudan, and India $[11,13]$. Being prevalent in such countries with low-low socioeconomic status, malnutrition, and sub-standard hygienic practices, it affects poor populations in remote areas that lack basic health facilities, trained medical staff, diagnostic tools, and treatment. These things make it to the list of neglected tropical diseases (NTDs), as recognized by the World Health OrganisationOz $[8,11]$.

In comparison with actinomycetes, eumycetoma is reportedly less responsive to medical treatment, which is regarded as problematic and challenging task. Treatment of actinomycetes can result with a cure rate up to $90 \%$, whereas eumycetoma is reported to exhibit resistance to antifungals like itraconazole and ketoconazole [8]. The entire landscape of treatment is based on the location, dissemination, and severity of the disease, which is completed either with the prolonged chemotherapy or surgical intervention $[8,14]$. In countries with sub-standard medical support, extension of the disease may lead to chronic progressive lesions, which in turn lead to amputation $[8,15]$.

In general, the treatment outcome of eumycetoma is suboptimal and unsatisfactory in many patients. But this can be overturned with the utilization of herbal medications, which prove to be cost-effective and acceptable in terms of medical complications like adverse health effects. Several medicinal plants like Moringa oleifera, Acacia nubica, Nigella sativa, and Boswellia papyrifera have already been recognized for comprising several phytochemicals with potential antifungal properties $[16,18]$. Thus, advanced research could surely be able to deliver phytotherapeutic agents against eumycetoma. In this review, we emphasis on the eumycetoma, elements of its infection and transmission, extended pathogenicity and phytotherapy. Our object is to highlight the perspective on futuristic approaches that could aid the phytochemical-based drug discovery process.

\section{GLOBAL PREVALENCE OF EUMYCETOMA}

\subsection{Distribution}

Most of the studies do not report eumycetoma as a separate disease. The statistics gathered from the sources depict the status of collective mycetoma patients all around the globe. However, eumycetoma is prevalent in only few of the countries that comes under the "Mycetoma belt" $[11,13]$. One must notice that these countries belong either to the under-developed or developing category. Suboptimal socio-economic standards in these countries have surely affected the people living in rural areas, with most of them being economically weak. These aspects evenly affect the medical supporting, with deficient instrumentation and staff [19]. Such limitations could even affect the reporting of cases, further diminishing the data for research and development. For example, there are only 8,763 reported mycetoma cases hitherto which, are expected to be much higher escalating [20]. Yet there is no separate report of eumycetoma cases. Among these, most of the cases were reported from Sudan $(>7,000)$, among which $70 \%$ of them are detected with the fungus $M$. mycetomatis. The country appears to be the most endemic country with a prevalence of $14.5 \%$ per 1,000 population. In Mexico, 3,933 cases have been reported in 54 years (mean 73 per year), where $3.5 \%$ of them were eumycetoma [6]. Another study reported 1,392 cases in India. Although these numbers seem to be outdated, efforts put by these have revealed the extensive pathogenesis, even in the countries outside the Mycetoma belt. Reports from Mali and Mauritania depict the rate as 5.4 and 69.7 cases per year, respectively. Apart from this, cases were also reported from Rumania, Nigeria, Uganda, Bulgaria, and Thailand. There is no overall study performed to determine the prevalence of the eumycetoma at world-wide scenario. Moreover, it is not considered as a reportable disease; thus, much remains unknown about the same [21].

\subsection{Pathogenicity}

Mycetoma affects more men than women. About 4,060 males were affected all over the world except Tunisia and Thailand, in comparison with 1,175 women. No occupation is exempt yet farmers and herdsmen are majorly affected. In Thailand, the ration is nearly 50:50, with 8 men and 9 women affected. Contrastingly, more women (16) were affected in Tunisia, compared to men (12). Only 5,240 cases reported with ages, where $70 \%$ of them $(3,664$ cases) found in the age group between 11 and 40. In all the studies, foot was the most affected organ $(68.7 \%)$, followed by hands (15\%), leg $(9.9 \%)$, trunk $(6.1 \%)$, and arm (4.0\%) which have been shown in Figure 1. In South American patients, trunk was the most affected portion in comparison with patients from Sudan (1.4\%) and Mexico (18.7\%) [22,23]. The discrepancies exist in the reports; despite they are conducted on world-wide basis. This may be attributed to the differences in maintaining the actual medical records of the disease. Furthermore, mycetoma is believed to affect children unevenly with $3.0 \%-4.5 \%$ of cases in 


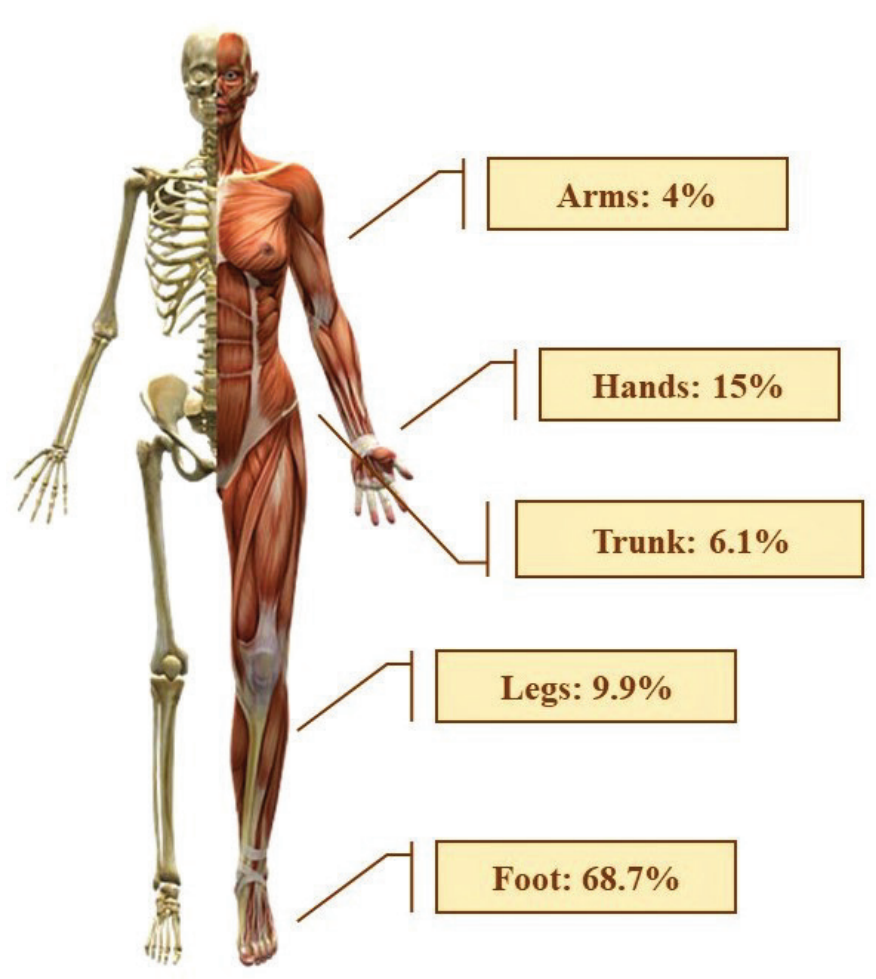

Figure 1: Body parts affected by mycetoma.

endemic regions. Children share similar clinical presentations and diagnostic revelations with the adults. However, shorter duration of infection and early diagnosis often result in lower amputation rates. But still there is a risk of children getting social outcasts, followed by the impact of disease on their personal and educational life [6].

\subsection{Etiology}

The predominant dematiaceous fungi differ from one to another region of the world, depending on the climatic factors, especially on annual rainfall. Diverse class of moulds have been involved in the pathogenesis, and it has been a difficult task tracking them [22]. For example, it is reported that 219 of the fungi have not been identified at the genus level. Presence of diverse class of fungi makes it even more difficult to treat, as the biological impacts vary based on differential pathogenesis of these fungi. Out of several such fungi, only $M$. mycetomatis is regarded as the most common etiological agent, which is responsible for about $24.3 \%$ of the cases studied. In addition, M. grisea, L. senegalensis, and P. boydii are responsible for $90 \%$ of the cases [5,21]. Madurella mycetomatis is prevalent in Africa, South America, and India. L. senegalensis is found commonly in West Africa, and M. grisea in South America. However, several fungal species represent very rare amount of infection around the world $[5,11,22]$.

\section{PATHOGENESIS AND CLINICAL MANIFESTATION}

\subsection{Host Factors}

Pathogenesis of eumycetoma involves three types of tissue reactions that coexist in the host body. In type 1 reactions, neutrophils play the principle role by surrounding the grains formed. Further they invade the grains and dismantle them. Granular immune cells, mononuclear cells were reported to be oriented towards fibrous tissue. Hypertrophy and hyperplasia are also reported to occur in the sweat glands. In type 2 reactions, neutrophils are replaced by macrophages and multinucleated cells that engulf the grains. Type 3 reactions are like type 1 and 2, except the fact that remnant fungal material is surrounded by a well organized epithelioid granuloma [23]. These inflammatory responses do not eliminate the grains. Giant cells with hyphae are expected to escalate the grain formation further. Presence of neutrophils and grains in the regional yet normal lymph nodes indicates the presence of the eumycetoma. In advanced cases, fibrosis is reported to substitute the lymphoid tissue [2]. Apart from this, T-cell responses are also present in eumycetoma patients. Significantly higher levels of Th-1 cytokines including interleukins, interferon, and tumor necrosis factor (IL-1 $\beta$, IL-2, IFN- $\gamma, \mathrm{TNF}-\alpha$ ), and lower levels of Th-2 cytokines (IL-4, IL-5, IL-6, IL-10) were found in patients undergone surgical excision, in comparison with those who did not undergone the same [24]. It is supported by the presence of Th-2 like responses including IL-10 and IL-4 were found in primary lesions and draining sinuses caused by the peripheral mononuclear cells by $M$. mycetomatis antigens. In addition, macrophages stimulated with $P$. boydii conidia also generated Th-2 response, whereas hyphae induced Th-1 response. The Th-1 responses are generally observed during acute phase of infection [6]. To this date, there is no report on the presence of humoral antibody response in case of eumycetoma.

\subsection{Pathogenic Factors}

Several pathogenic factors play a role in survival of the fungus in the host body against the defense mechanisms. Madurella mycetomatis is reported to produce melanin pigments that protect pathogens against antifungal drugs, ultraviolet radiation, alveolar macrophages, enzymatic lysis, and oxidative agents. The schematic diagram representing the role of melanin in pathogenesis has been given in Figure 2. Melanin is suspected to play a key role in the pathogenesis of the moulds. For example, an in vitro study using fungal strains $M$. mycetomatis showed that melanin production in the fungi could elevate the minimum inhibitory concentrations (MICs) of antifungal drugs like ketoconazole (32-fold) and itraconazole (64-fold) [25]. Fungi are believed to possess several melanin biosynthetic mechanisms like 1,8-dihydroxynaphthalenemelanin pathway, L-dopamine pathway, and pyomelanin pathway [25-27]. This further induces resistance to the antifungal drugs used by the host, where the efficacy of the drug is reduced by pathogen to survive in the host. Histological evidences claim that presence of lipids, proteins, and heavy metals, alongside melanin in the grain cement matrix avoids the entry of antifungal agents [28]. The fungus $M$. mycetomatis is also found resistant to different combinations of antifungal drugs, including amphotericin B, itraconazole, and terbinafine [29]. Further, the fungi tend to decrease the activity of chitotriosidase, which tends to eliminate the fungi by binding to chitin in the mycetoma grain [30].

\subsection{Clinical Manifestation}

Both actinomycetoma and eumycetoma share virtual similarities in terms of clinical symptoms, despite caused by different 


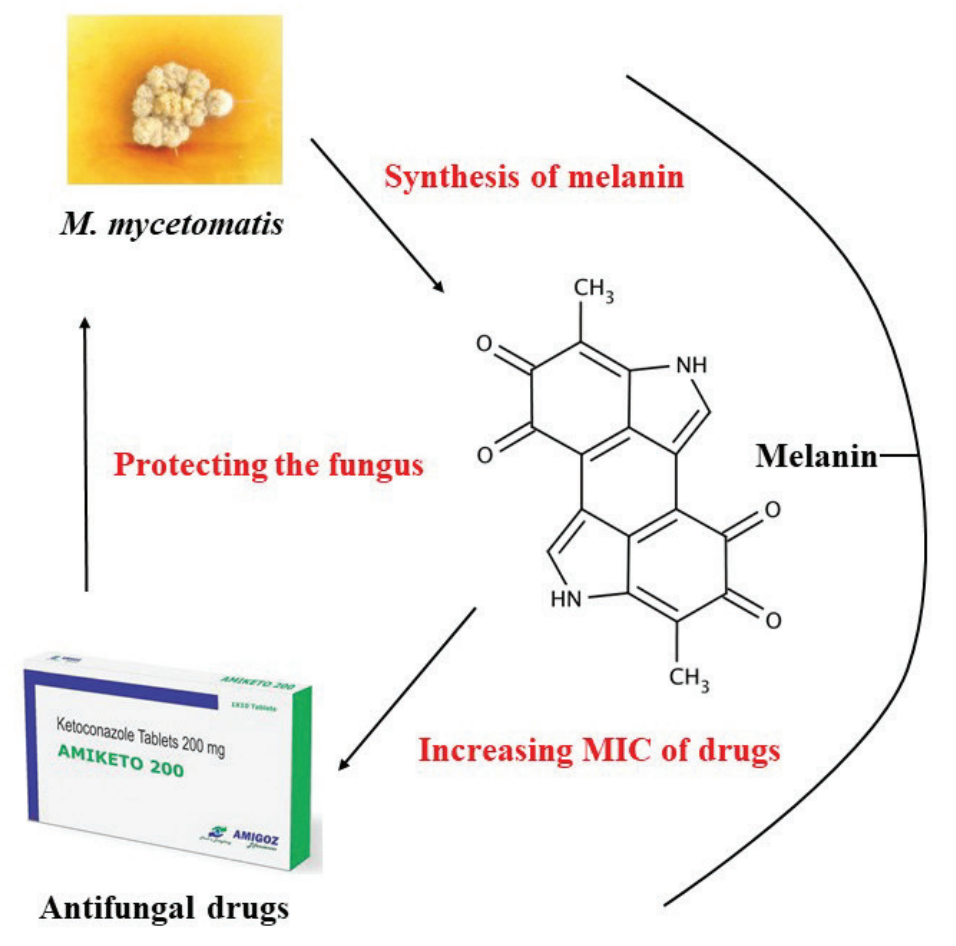

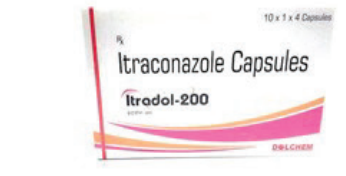

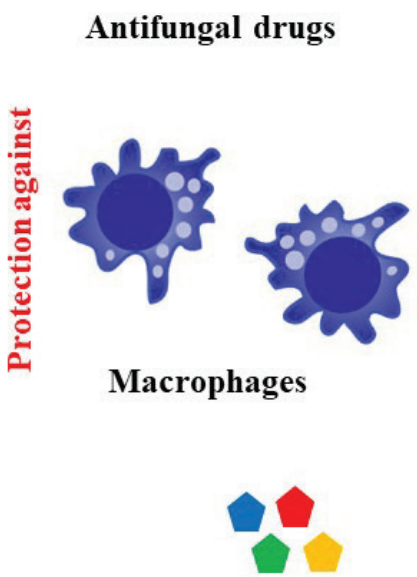

Oxidative agents

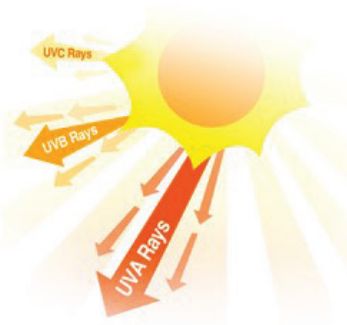

\section{UV radiation}

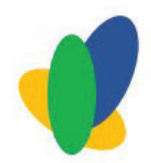

Enzymatic lysis

Figure 2: Role of melanin synthesized by $M$. mycetomatis in pathogenesis of eumycetoma.

etiological agents. However, eumycetoma appears to be less aggressive and destructive in comparison with actinomycetoma, where the latter is found invading the bones earlier than eumycetoma [31]. Asymptomatic infection leads to the development of pathogens to develop in the host undetected for several years. The time between initial infection and consultation could vary from 3 months to 50 years [6]. This is attributed to the poor health facilities, absence of economic aid, lack of health education, delayed and painless progression of lesions, and fear of amputation. A study published in 2014 based on the survey conducted in an endemic Sudanese village has shown that $96 \%$ of the villagers had substandard level of understanding about mycetoma, and only $49 \%$ of them practiced safety measures [32]. The triad of painless swelling, draining sinuses, and discharge consisting grains is a characteristic feature of eumycetoma. These grains may be yellow, black, white or pale, and yellowish-brown based on the etiological agent [11].

The infection begins with the breach of the skin through which the pathogen gains the entry and later spreads to the different regions including tissues, forming sinuses. Skin exhibits a painless and tender wooden induration. The cystic, solid mass thus formed results in tissue damage, deformation, and loss of function [33]. Direct spread to the spinal cord and vertebral bodies could result in paraplegia. Sometimes lesions in the skull can cause bone damage with subsequent neural degeneration. Bone invasion can produce cavities filled with cement-like matrix that comprises grains and fibrous tissue. The stability provided by the fibrous tissue makes it uncommon to have pathological fractures. Purely osteosclerotic lesions can be seen in case of skull infection, where the dense bone formation is observed, with dense bone formation [34]. The hyperplasia and hypertrophy of sweat glands beneath the lesions result in increased sweating. The elevated temperature is due to the inflammatory responses, which involve a series of interconnected molecular mechanisms [2,23]. Dilated arteries and veins depict the increased blood flow to the lesion. Apart from tissues, tendons and nerves are rarely affected until the extremity is reached. As the pain is absent, tracts of subcutaneous tissue get filled with mass. Metastatic lesions could occur at various lymph node regions, which might turn into suppurative. Lymph nodes are said to be recurrent and could be seen in case of surgery. Meanwhile, hematological spread is also possible. Madurella mycetomatis is reported to occur in intact blood vessels of the spinal mycetoma $[31,35]$.

\subsection{Mode of Transmission}

Culturing of fungi including M. mycetomatis has been a failed attempt, though the DNA samples were found to be detected in soil and samples [36]. This indicates the presence of fungi in soil and thorns, from which the disease spreads upon interaction with the hosts. The available evidence suggests that the fungi could be dung-inhabiting, providing a new dimension to the phylogenetic analyses that investigate the natural fungal origin [37]. This was supported by the detection of thorn remnants in the lesions of mycetoma patients suggest the possible entry of fungi through trauma like cuts, and wounds [38]. Further, there is no data available on primary reservoirs that help in the transmission. Studies need to investigate the possible role of domestic animals like donkeys, cattle, sheep, chicken, and dogs that live in proximity with humans. 


\section{DETECTION AND DIAGNOSIS}

\subsection{Imaging}

In scarcity of basic health facilities, diagnosis is carried out using ultrasound and fine needle aspiration. These are the minimal requirements used to confirm the diagnosis in clinical practice and are believed to diagnose most of the cases. Out of these, ultrasound is a preferred imaging technique that is commonly found in health institutions in endemic areas. It clearly distinguishes eumycetoma from other masses in subcutaneous tissue [39]. Appearance of sharp-reflective echoes which are probably caused by grain's cementing substance shows the presence of grains. Especially, cavities either with presence or absence of acoustic enhancement can be seen in case of eumycetoma. Based on grain size, type of embedding, and nature of cement, eumycetoma and actinomycetoma are differentiated. The technique is efficiently used to define the extent of lesion, which could be further utilized for surgical intervention [40].

Radiography is also an imaging technique that is used in peripheral hospitals. A survey conducted on 516 patients diagnosed with radiography revealed that only $3 \%$ had a normal radiograph of the affected limb. Among other abnormalities observed, soft tissue swelling was more common (93\%), followed by (56\%), and bone invasion (46\%). In addition, bone cavities (32\%) and osteoporosis (32\%) were also observed [41]. Among computerized tomography (CT) tests, helical CT is comparatively more advanced than plain $\mathrm{CT}$, as the former allows 3-dimensional reconstruction and generates precise results on the extent of organ involvement. Helical CT also aids in the visualization of the vascular involvement [42]. Nonetheless, usage of modern approaches like magnetic resonance imaging (MRI) has proved its efficacy over the others, in terms of detecting the extent of lesion and invasion. MRI is believed to possess greater sensitivity than ultrasound, radiography, and CT. It also shows the dot-in-circle sign, which is an indication of fungal grains [43].

\subsection{Identification of the Pathogen}

Identification of the microorganism in the patients is a key to drive the treatment further. Grains are isolated from the sinuses discharging and are further examined in microscope. Isolation of grains from the deep is preferred over the peripheral because of the lack of viability and possible contamination associated with the latter. Isolation is done with the syringe, and the grains are crushed under cover glass. The size of the septation, filaments, shape, color, and other morphological characteristics are thoroughly examined. In case of eumycetoma, fine filaments are seen with periodic acidSchiff. This is followed by the culturing for 4 weeks. But the identification of the fungal species based on colony morphology could be difficult as they share similar morphology [23]. Apart from microscopic examination of grains, histopathology is also efficiently used by many research laboratories. Hemotoxylin and eosin stains are used to pre-identify the fungi. However, due to the similar appearance as in case of grain examination, fungal species share similar morphology, it becomes difficult to identify them at species level. For example, differentiation between Scedosporium boydii, Fusarium spp, Acremonium spp, and between Medicopsis romeroi, Exophiala jeanselmei, Falciformispora tompkinsii,
Falciformispora senegalensis, and Trematosphaeria grisea is difficult. Further, a fungus like M. mycetomatis makes it even more difficult to differentiate as they present multiple grain types during histological examination [6].

\subsection{Molecular Identification}

Although chemotaxonomic methods are effective in distinguishing the etiologic agents up to their respective genera, they are referred to as tedious, time-consuming, and laborious. The results generated by these techniques are not reliable as they lack vital information on species, sub-species, and types of grains produced. These are being complemented by molecular systematic procedures that use biomolecules like DNA and proteins to determine the species of the etiologic agents $[19,40]$. Methods like $16 \mathrm{~S}$ ribosomal RNA (rRNA) gene sequencing [44], polymerase chain reaction (PCR) [45], Curie-point pyrolysis mass spectroscopy, and PCR-randomly amplified polymorphic DNA fingerprinting [23]. Such techniques provide precise details on classification. Unfortunately, these procedures are yet to be deliberated in eumycetoma endemic areas $[19,40]$. In addition, specialized sequences known as internal transcribed spacer regions are usually amplified with the help of pan-fungal primers and are sequenced. Resultant sequences are compared with previous sequences available in databases like GenBank. This approach has led to the identification of pathogens at species level. New species like Madurella fahalii, Madurella tropicana, Madurella pseudomycetomatis have been identified with the help of these techniques $[6,46]$.

Development of techniques like PCR-restriction fragment length polymorphism has even resulted in the determination of homogeneity of M. mycetomatis isolates from thorn and soil samples. Another novel technique known as isothermal rolling circle amplification has generated results in 6 hours of time, in which it was reported to detect different fungal species. Molecular typing techniques like random amplified polymorphic DNA (RAPD), amplification fragment length polymorphism (AFLP), and restriction endonuclease (REN) analyses have been carried out successfully [47]. Although results from RAPD are variable, AFLP and REN analyses were found to differentiate $M$. mycetomatis isolates from different origins. In comparison with the chemotaxonomic methods, molecular diagnostics appears to be expensive, and cannot be affordable by all the patients [23].

\subsection{Serological Identification}

Furthermore, molecular techniques based on serological examination also provide precise information. Although no reliable serological tests exist to this date, efforts have been made to utilize the serum-based antibody-antigen reactions for the pathogen identification. They include indirect hemagglutinin assays, immunoblots, immunodiffusion, counterimmunoelectrophoresis, immunoblotting, immunodiffusion, and enzyme-linked immunosorbent assay (ELISA). In case of eumycetoma, serological tests have been used for $P$. boydii and M. mycetomatis [6]. Indirect hemagglutinin assays, counterimmunoelectrophoresis, and immunodiffusion use crude non-standardized antigens, and do not meet up the required specificity and sensitivity. Further, an ELISA analysis based 
on $M$. mycetomatis pure antigens that included recombinant produced translationally controlled tumor protein (TCTP), and luminex assays based on TCTP-fructose-bisphosphate aldolase, and pyruvate kinase also showed insignificant specificity, without differentiating between patients and healthy controls. Therefore, effective diagnosis could be achieved either with reliable imaging, histological examination, molecular typing, or with advancements in serological tests to improve sensitivity and specificity [19].

\section{THERAPEUTICS AND LIMITATIONS}

Several chemotherapeutic agents that have been employed to treat eumycetoma were once experimented with common fungi. These antifungal drugs exhibit different mechanisms to either inhibit or to kill the fungus [48]. Much remains unknown of their mechanisms to eliminate the fungus. The chemotherapy exists for 18-24 months prior surgical intervention. The response to these drugs has been poor and has left many patients are unsatisfied. Thus, a combination of surgery and chemotherapy is preferred. Currently, a class of drugs known as azoles have been recognized as effective against eumycetoma [11,49]. Ketoconazole was used as a mainstream therapeutic agent at $400-800 \mathrm{mg} /$ day for 9-12 months. However, it was restricted in 2013 for its adverse effects like drug interactions, potentially fatal liver injury, and problems with adrenal gland by the U.S. Food and Drug Administration (FDA) [50]. For the same reasons, marketing authorizations of ketoconazole were called off by European Medicines Agency. Currently, itraconazole is used to treat infections, but it is reported with incomplete cure [51]. Melanin production in the fungi could elevate the MICs of antifungal drugs like ketoconazole (32-fold) and itraconazole (64-fold), thus increasing the resistance to the next level [25]. In a similar fashion, terbinafine has been employed to treat small numbers of infections with limited efficiency [51].

Posaconazole and voriconazole have been evaluated in limited cases yet yielding promising results. Although good in vitro activity has been recorded, therapy involves a long duration [51]. In addition, fosravuconazole and Isavuconazole were found to possess profound in vitro activity. However, unlike itraconazole, MICs of fluconazole, voriconazole, amphotericin B are not affected. Pathogens are reported to exhibit susceptibility towards these drugs [25], except the fact that amphotericin B has reported with suboptimal in vitro activity and toxicity level. There is only minimal amount of data exists on the liposomal activity that the drug, which is essential to be deciphered, to determine the antifungal activity. In addition, it has been proved that $M$. mycetomatis is resistant to class of echinocandins as well [5254]. Dose dependent studies regarding the MIC determination of posaconazole are yet to be conducted. In view of these figures, voriconazole could be effectively used as a monotherapeutic agent, yet considering risk factors like emergence of resistant fungal strains. Although itraconazole (200-400 mg/day) is considered for current treatment, its inability to cure the disease has been put forward [25]. Thus, a clinically proven, efficient, and safe antifungal drug with short duration of treatment is essential for eumycetoma. But considering the economic and social conditions, it would take years to develop such a drug. Frustrated with prolonged and expensive treatment, some of the Sudanese patients have been reverted to herbal treatment. But this has led to adverse effects and further delay in treatment [17]. In the coming sections, the efficacy of phytotherapy has been discussed in perspective of developing plant-based drug.

\section{MEDICINAL PLANTS WITH THERAPEUTIC POTENTIAL}

\subsection{Acacia nubica Benth.}

Acacia nubica Benth. is an African origin medicinal shrub belonging to the family of Leguminosae-Mimosoideae. It is mainly found in African countries like Sudan, Egypt, Ethiopia, Uganda, Kenya, Tanzania, Arabia, and Kenya. It measures up to $1-5 \mathrm{~m}$ from the base, with grayish-white to yellowish-green branchlets. The plant is inhabited to dry and rocky soil. With stipular spines and pinnately arranged leaves, the plant appears as a thorny shrub spread on the land $[55,56]$. A recent evaluation showed that defatted methanol extract of the plant root bark could inhibit the fungal growth at $\mathrm{MIC}_{50}$ value of $4 \mu \mathrm{g} / \mathrm{ml}$, which ranged between 0.5 and $128 \mu \mathrm{g} / \mathrm{ml}$ during the experiment conducted on M. mycetomatis [18]. However, there was no significant activity reported by this study. With no individual component with antifungal potential reported, $A$. nubica requires further attention of researchers to obtain antifungal constitutes. With the chemical extraction followed by the application of standard drug discovery procedure, phytochemcials of the plant could be efficiently used for treating eumycetoma.

\subsection{Nigella sativa Linn.}

Nigella sativa is an annual flower plant commonly known as black cumin or black caraway. It belongs to the family of Ranunculaceae, and can be found in Middle Eastern Mediterranean region, Northern Africa, Southern Europe, Indian subcontinent including India, Pakistan, Saudi Arabia, Turkey, and Syria. The plant usually grows up to $12 \mathrm{~m}$ in length with finely divided leaves. Flowers are blue to white colored and delicate. Fruits are large and comprise follicles, which in turn contain numerous seeds that could be used as spice, a replacement to cumin seeds [57]. The plant is reported to possess a feeble anti-fungal activity against $M$. mycetomatis with $\mathrm{MIC}_{50}$ value of $4 \mu \mathrm{g} / \mathrm{ml}$, which ranged between 0.25 and $128 \mu \mathrm{g} /$ $\mathrm{ml}$. The gas chromatography-mass spectrometry analysis of the plant is yet to be conducted to reveal the phytochemical diversity of the plant, as there were no components reported during the study [18]. Alongside A. nubica, N. sativa could also be applied with drug discovery procedures to develop plant-based drugs with antifungal potential.

\subsection{Boswellia papyrifera (Del.) Hochst}

Boswellia papyrifera (Del.) Hochst, also known as Sudanese frankincense, is a flowering plant of African origin and native to the countries Eritrea, Ethiopia, and Sudan. Being a member of the family Burseraceae, the plant could grow up to $12 \mathrm{~m}$ of length with a straight regular bole and rounded crown. Leaves are large and compound. It usually grows on river gorges, grasslands, and rough soil. The mature tree is protected by bark which comprises resin, which is said to have diverse nature of chemical constituents that could be exploited for the medicinal purposes $[58,59]$. In a 


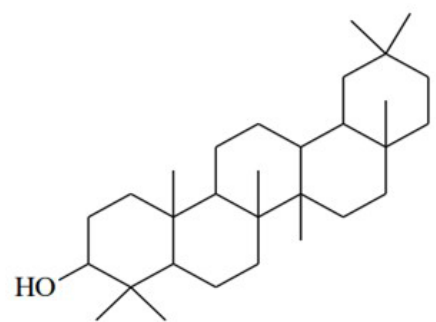

a) $\beta$-amyrin

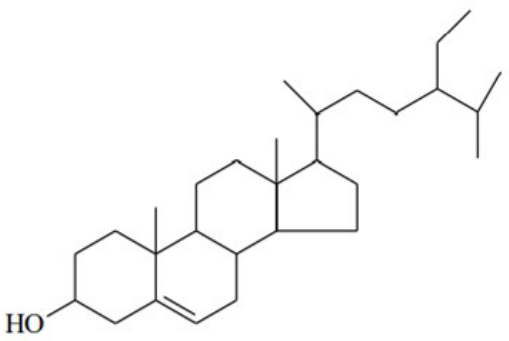

c) $\beta$-sitosterol

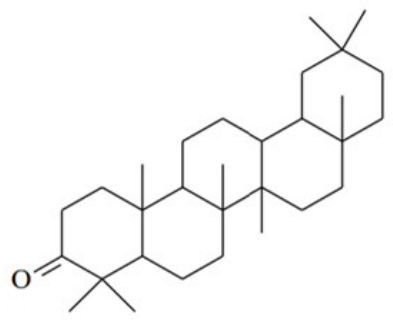

b) $\beta$-amyrone

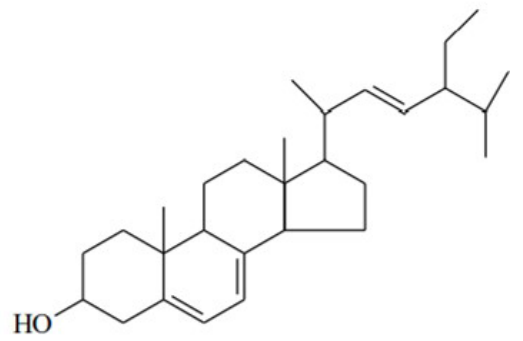

d) stigmatriene

Figure 3: Triterpenoids from B. papyrifera with antifungal activity.

recent evaluation, gum resin of the plant using different extracts examined for antifungal activity against $M$. mycetomatis. Defatted methanol extract of $B$. papyrifera gum resin showed an $\mathrm{MIC}_{50}$ value of $1 \mu \mathrm{g} / \mathrm{ml}$, which was ranged between 0.5 and $128 \mu \mathrm{g} / \mathrm{ml}$. This was low and efficient in comparison with other plants reported (A. nubica and N. sativa). It has also been reported that the crude methanol extract comprises triterpenes like $\beta$-amyrone, $\beta$-amyrin, and stigmatriene, whereas soluble ethyl acetate extract contains $\beta$-sitosterol in addition to the three components listed above (Fig. $3)$. Furthermore, the in vitro antifungal activity of these individual compounds revealed that, $\mathrm{MIC}_{50}$ values of $\beta$-amyrin $(0.5->256$ $\mu \mathrm{g} / \mathrm{ml}), \beta$-amyrone $(0.25->128 \mu \mathrm{g} / \mathrm{ml}), \beta$-sitosterol $(0.125->128$ $\mu \mathrm{g} / \mathrm{ml})$, and stigmatriene $(0.125->128 \mu \mathrm{g} / \mathrm{ml})$ were significantly lower than that of crude extracts [18]. These findings show that plants like $B$. papyrifera should be evaluated for the individual compounds that possess antifungal activity.

\subsection{Melaleuca alternifolia}

Melaleuca alternifolia, popularly known as tea tree is a tall shrub used worldwide for the commercial production of tea tree oil. Being a member of the family Myrtaceae, it is endemic to the Australia and grows on swampy areas and alongside streams. The mature tree grows up to $7 \mathrm{~m}$, surrounded by thin and whitish bark with a bushy crown. Leaves are whorled and contain numerous oil glands. Flowers are small, whitish cream colored and give a fluffy appearance in the spring season. Tree bears small woody, cup-shaped fruit that are present all over the branches [60,61]. A study conducted using tea tree oil on $M$. mycetomatis depicted the MIC of the range $0.008 \%-0.25 \%(v / v)$. The study revealed that a mere concentration of $0.06 \%(\mathrm{v} / \mathrm{v})$ was required to reduce $50 \%$ of the fungal isolates and $0.25 \%(v / v)$ required to reduce $90 \%$ of the same. The study also predicts the presence of $40 \%$ terpinen- $4-o l$ could be able to penetrate through the fungal cell wall and could be used as topical agent against the infection [16]. Advanced studies in this regard are essential to decipher the complete phytochemical as well as antifungal profile to develop plant-based drugs against eumycetoma.

\subsection{Other medicinal plants}

$M$. oleifera is a fast-growing, drought-resistant tree belonging to the family Moringaceae, and is commonly found in Indian subcontinent [62]. Though the plant is believed to possess significant antifungal activity, it has been neglected since many years since the incident of Sudanese patients declining the herbal treatment. But further examinations, including dose-dependent in vivo studies could reveal the actual true potential of the plant [17]. Zingiber officinalis or ginger is a flowering plant originating from Southeast Asia of Zingiberaceae family, whose rhizome is extensively utilized as a spice as well as a folk medicine [63]. Even though the rhizome part is believed to possess anti-fungal activity, plant failed to deliver the accurate results at expected rate [18]. Advanced assessments could further be carried out in a dose dependent manner to completely depict the antifungal potential of the plant. In addition, Piper nigrum is a flowering vine of Indian origin belonging to the family Piperaceae commonly known as black pepper or pepper. Seeds of the plant are extensively used as spice and folk medicine [64]. Fruit extract of the plant needs more attention like that of Z. officinalis [18]. Further, Eugenia caryophillus or clove is an evergreen aromatic plant bears flowering buds that are used as spice for their unique aroma. It belongs to the family of Myrtaceae and is native to the Southeast Asia [65]. Cinnamomum verum also known as true cinnamon tree, is a member of the family Lauraceae, and is commonly found in Southeast Asian countries [18]. Like all the other plants described 
Table 2: A summary of phytotherapy against Eumycetoma.

\begin{tabular}{|c|c|c|c|c|}
\hline Categories & & & Particulars & \\
\hline Plant species & A. nubica & N. sativa & B. papyrifera & M. alternifolia \\
\hline Fungi species & M. mycetomatis & M. mycetomatis & M. mycetomatis & M. mycetomatis \\
\hline Type of study & in vitro & in vitro & in vitro & in vitro \\
\hline Control & Inoculum and solvent & Inoculum and solvent & Inoculum and solvent & Artemisinin, itraconazole \\
\hline Result & $\begin{array}{l}\mathrm{MIC}_{50} \text { value of } 4 \mu \mathrm{g} / \mathrm{ml} \text {, } \\
\text { which ranged between } 0.5 \\
\text { and } 128 \mu \mathrm{g} / \mathrm{ml}\end{array}$ & $\begin{array}{l}\mathrm{MIC}_{50} \text { value of } 4 \mu \mathrm{g} / \mathrm{ml} \text {, } \\
\text { which ranged between } \\
0.25 \text { and } 128 \mu \mathrm{g} / \mathrm{ml}\end{array}$ & $\begin{array}{l}\text { MIC }_{50} \text { value of } 1 \mu \mathrm{g} / \mathrm{ml} \text {, which was ranged between } 0.5 \\
\text { and } 128 \mu \mathrm{g} / \mathrm{ml}\end{array}$ & MIC values of the range $0.008 \%-0.25 \%(v / v)$ \\
\hline Inference & $\begin{array}{l}\text { Confirmed antifungal } \\
\text { activity }\end{array}$ & $\begin{array}{l}\text { Confirmed antifungal } \\
\text { activity }\end{array}$ & $\begin{array}{l}\text { Significant antifungal activity with confirmed chemical } \\
\text { compounds with } \mathrm{MIC}_{50}: \beta \text {-amyrin }(0.5->256 \mu \mathrm{g} / \\
\mathrm{ml}), \beta \text {-amyrone }(0.25->128 \mu \mathrm{g} / \mathrm{ml}), \beta \text {-sitosterol } \\
(0.125->128 \mu \mathrm{g} / \mathrm{ml}) \text {, and stigmatriene }(0.125->128 \\
\mu \mathrm{g} / \mathrm{ml})\end{array}$ & $\begin{array}{l}\text { Concentration of } 0.06 \%(\mathrm{v} / \mathrm{v}) \text { required to reduce } \\
50 \% \text { of the fungal isolates and } 0.25 \%(\mathrm{v} / \mathrm{v}) \\
\text { required to reduce } 90 \% \text { of the same. Possible } \\
\text { fungal cell wall penetration by available } 40 \% \text { of } \\
\text { terpinen- } 4 \text {-ol }\end{array}$ \\
\hline $\begin{array}{l}\text { Antifungal } \\
\text { mechanism }\end{array}$ & Not defined & Not defined & $\begin{array}{l}\text { Possible anti-inflammatory activity against mycetoma } \\
\text { wounds. Confirmed antifungal activity of triterpenoids } \\
\beta \text {-amyrin, } \beta \text {-amyrone, } \beta \text {-sitosterol, and stigmatriene }\end{array}$ & $\begin{array}{l}\text { Possible antifungal activity of terpinen-4-ol, an } \\
\text { essential oil component that inhibits the growth } \\
\text { of the fungi }\end{array}$ \\
\hline
\end{tabular}

Adapted from van de Sande et al. [16] and Elfadil et al. [18].

above, it is used as a spice [66]. Along with the Z. officinalis and $P$. nigrum, the plant needs to be assessed further for potential antifungal activities. A summary of phytotherapy has been depicted in Table 2 .

\section{PERSPECTIVES AND PROJECTIONS}

Eumycetoma has been an ominous infectious disease that has been categorized under NTDs. The extensive lethality is equally attributed to the economical setbacks of the developing countries, people with substandard level of education and awareness about health. The chemotherapeutic agents have been used so far have not given good results except itraconazole; but the risk of adverse effects and possible drug resistance prevail the efforts of public health agencies and researchers [19,51]. In the vista, phytochemcials from various plants irrespective of their total medicinal potential could be useful in treating eumycetoma. It could be a noteworthy effort to induce health awareness programs in endemic regions to practice safety measures while working, as the fungal invasions occur through open wounds. In addition, people must be advised to go for timely diagnosis, which could substantially reduce the burden of the disease. This could be further modified with contributions from different sectors of the society, including scientists, academics, non-governmental organizations, pharmaceutical companies, and health officials to practice "One-Health Approach" [67]. Designing efficient and accurate diagnostic tools and techniques like DNA sequencing, 16S rRNA, PCR, PCR-restriction fragment length polymorphisms, PCRRAPD, and AFLP has been done [6]. However, advanced methods like RNA interference technology, and proteomic analysis for possible target search need to be developed.

In the treatment sector, development of chemotherapeutic models for the drug analysis, targeting the virulent proteins and enzymes for the inhibition of the associated pathogenic mechanisms could be practiced. Even in this regard, there have been some gaps to be taken care of. Most of the people cannot afford these expensive diagnostic and therapeutic tools, as they are economically backward. Considering these options, treatment of the infected becomes difficult despite colossal amount of research and funding [19].
As many of the endemic countries belong to the substandard levels in the global economy, it becomes essential to utilize available natural resources as a source of medicine. Thus, usage of costeffective measures like phytotherapy becomes a feasible approach. A limited amount of research has been conducted in herbal treatment $[16,18]$. Though it takes a considerable amount of time to develop plant-based drugs, one must notice the resistance of the fungi to the available chemical therapeutic agents, that in turn could reverse the entire landscape of treating eumycetoma. The reported phytochemicals can be easily extracted from highly efficient plants like $B$. papyrifera. These phytochemical compounds need to be characterized, evaluated for their cytotoxic effects and possibilities of their synthesis in vitro conditions need to be studied. In addition, qualitative and quantitative assays using individual compounds in a dose dependent and combination approaches could reduce the burden of multifactorial results. These isolated compounds could be further modified according to the requirement based on cytotoxic evaluations done in primary screening. These compounds could be analyzed in silico for effective binding and inhibitory effect on specific component or any part of the identified target. Further, the bioavailability of the compounds could be dealt to modify the compound to match the physiological conditions of the target organ. Usage of in silico methods like molecular modeling and docking could save time and money spent for pre-clinical trials. Following these protocols would surely help the treatment of eumycetoma through phytotherapy.

\section{CONCLUSION}

Eumycetoma has been an extensively pathogenic and drugresistant fungal ailment spread all over the world, especially in Mycetoma belt. The invasive infection of this disease is attributed to both the causative agents that resist the therapeutic treatment. It is equally supported by the humans practicing no safety measures and deficient medical treatment, due to poor economic background. The review focuses on the various factors of the disease like infection, transmission, epidemiology, pathogenesis, diagnosis, available therapeutic agents, and phytotherapy. The aim of the review is to highlight the role of medicinal plants and their constituents, which may aid the phytochemical based 
approach to cure the disease. No major research breakthrough has been completed in this aspect, leaving behind much of the facts unknown about the reported phytochemcials from the plant extracts. This review has highlighted the work done so far, in the phytotherapeutic approach and it further dwells on the requisite in research and development. It can thus be concluded that with the following of projections discussed, it could be easier to find a plant-based cure for eumycetoma.

\section{AUTHOR CONTRIBUTIONS}

All authors made substantial contributions to conception and design, acquisition of data, or analysis and interpretation of data; took part in drafting the article or revising it critically for important intellectual content; agreed to submit to the current journal; gave final approval of the version to be published; and agree to be accountable for all aspects of the work. All the authors are eligible to be an author as per the international committee of medical journal editors (ICMJE) requirements/guidelines.

\section{FUNDING}

There is no funding to report.

\section{CONFLICTS OF INTEREST}

The authors report no financial or any other conflicts of interest in this work.

\section{ETHICAL APPROVALS}

Not applicable.

\section{PUBLISHER'S NOTE}

This journal remains neutral with regard to jurisdictional claims in published institutional affiliation.

\section{REFERENCES}

1. Reis CM, Reis-Filho EG. Mycetomas: an epidemiological, etiological, clinical, laboratory and therapeutic review. An Bras Dermatol 2018;93(1):8-18.

2. Relhan V, Mahajan K, Agarwal P, Garg VK. Mycetoma: an update. Indian J Dermatol. 2017;62(4):332.

3. Hjira N, Boudhas A, Al Bouzidi A, Boui M. Madura foot: report of a eumycetoma Moroccan case. J Dermatol Surg 2015;19(2):143-5.

4. Emmanuel P, Dumre SP, John S, Karbwang J, Hirayama K. Mycetoma: a clinical dilemma in resource limited settings. Ann Clin Microbiol Antimicrob 2018;17(1):35.

5. Verma P, Jha A. Mycetoma: reviewing a neglected disease. Clin Exp Dermatol 2019;44(2):123-9.

6. Zijlstra EE, Van De Sande WW, Welsh O, Goodfellow M, Fahal AH. Mycetoma: a unique neglected tropical disease. Lancet Infect Dis 2016;16(1):100-12.

7. Elkheir LY, Haroun R, Mohamed MA, Fahal AH. Madurella mycetomatis causing eumycetoma medical treatment: the challenges and prospects. PloS Negl Trop Dis 2020;14(8):e0008307

8. Welsh O, Al-Abdely HM, Salinas-Carmona MC, Fahal AH. Mycetoma medical therapy. PLoS Negl Trop Dis 2014;8(10):e3218.

9. Boroujeni ZB, Hashemi SJ, Ghazvini RD, Khodavaisy S, Zareei M, Hosseinpour L, et al. Recurrent eumycetoma caused by novel species Madurella pseudomycetomatis: a case report. Med Mycol Case Rep 2019;26:13-5.
10. Afroz N, Khan N, Siddiqui FA, Rizvi M. Eumycetoma versus actinomycetoma: diagnosis on cytology. J Cytol 2010;27(4):133.

11. Nenoff P, Van De Sande WW, Fahal AH, Reinel D, Schöfer H. Eumycetoma and actinomycetoma-an update on causative agents, epidemiology, pathogenesis, diagnostics and therapy. J Eur Acad Dermatol Venereol 2015;29(10):1873-83.

12. World Health Organisation (WHO). Mycetoma. Updated on $21 \mathrm{st}$ June 2019. Available via https://www.who.int/news-room/fact-sheets/ detail/mycetoma (Accessed 4 September 2020)

13. Bonifaz A, Tirado-Sánchez A, Calderón L, Saúl A, Araiza J, Hernández $\mathrm{M}$, et al. Mycetoma: experience of 482 cases in a single center in Mexico. PloS Negl Trop Dis 2014;8(8):e3102.

14. Fahal AH, Rahman IA, El-Hassan AM, Rahman MA, Zijlstra EE. The safety and efficacy of itraconazole for the treatment of patients with eumycetoma due to Madurella mycetomatis. Trans R Soc Trop Med Hyg 2011;105(3):127-32.

15. Fahal AH. Management of mycetoma. Expert Rev Dermatol 2010;5(1):87-93.

16. van de Sande WW, Fahal AH, Riley TV, Verbrugh H, van Belkum A. In vitro susceptibility of Madurella mycetomatis, prime agent of Madura foot, to tea tree oil and artemisinin. J Antimicrob Chemother 2007;59(3):553-5.

17. Ezaldeen EA, Fahal AH, Osman A. Mycetoma herbal treatment: the mycetoma research centre, Sudan experience. PloS Negl Trop Dis 2013;7(8):e2400.

18. Elfadil H, Fahal A, Kloezen W, Ahmed EM, van de Sande W. The in vitro antifungal activity of sudanese medicinal plants against Madurella mycetomatis, the eumycetoma major causative agent. PloS Negl Trop Dis 2015;9(3):e0003488.

19. Van de Sande WW, Fahal AH, Goodfellow M, Welsh O, Zijlstra EE Merits and pitfalls of currently used diagnostic tools in mycetoma. PloS Negl Trop Dis 2014;8(7):e2918.

20. Centers for Disease Control and Prevention (CDC). Mycetoma. Updated on 27th May 2020. Available via https://www.cdc.gov/ fungal/diseases/mycetoma/index.html (Accessed 4 2020)

21. Van de Sande WW. Global burden of human mycetoma: a systematic review and meta-analysis. PloS Negl Trop Dis 2013;7(11):e2550.

22. Brandt ME, Warnock DW. Epidemiology, clinical manifestations, and therapy of infections caused by dematiaceous fungi. J Chemother 2003;15(Sup 2):36-47.

23. Ahmed AA, van de Sande W, Fahal AH. Mycetoma laboratory diagnosis. PloS Negl Trop Dis 2017;11(8):e0005638.

24. Nasr A, Abushouk A, Hamza A, Siddig E, Fahal AH. Th-1, Th-2 cytokines profile among Madurella mycetomatis eumycetoma patients. PloS Negl Trop Dis 2016;10(7):e0004862.

25. Van de Sande WW, de Kat J, Coppens J, Ahmed AO, Fahal A, Verbrugh $\mathrm{H}$, et al. Melanin biosynthesis in Madurella mycetomatis and its effect on susceptibility to itraconazole and ketoconazole. Microbes Infect 2007;9(9):1114-23.

26. Schmaler-Ripcke J, Sugareva V, Gebhardt P, Winkler R, Kniemeyer $\mathrm{O}$, Heinekamp T, Brakhage AA. Production of pyomelanin, a second type of melanin, via the tyrosine degradation pathway in Aspergillus fumigatus. Appl Environ Microbiol 2009;75(2):493-503.

27. Medina R, Lucentini CG, Franco ME, Petroselli G, Rosso JA, Erra-Balsells $\mathrm{R}$, et al. Identification of an intermediate for 1, 8-dihydroxynaphthalene-melanin synthesis in a race-2 isolate of Fulviafulva (syn. Cladosporiumfulvum). Heliyon 2018;4(12):e01036.

28. Ibrahim AI, El Hassan AM, Fahal A, van de Sande WW. A histopathological exploration of the Madurella mycetomatis grain. PloS one 2013;8(3): e57774.

29. Eadie K, Parel F, Helvert-van Poppel M, Fahal A, van de Sande W. Combining two antifungal agents does not enhance survival of Galleria mellonella larvae infected with Madurella mycetomatis. Trop Med Int Health 2017;22(6):696-702.

30. Verwer PE, Notenboom CC, Eadie K, Fahal AH, Verbrugh HA, van de Sande WW. A polymorphism in the chitotriosidase gene associated 
with risk of mycetoma due to Madurella mycetomatis mycetoma-a retrospective study. PloS Negl Trop Dis 2015;9(9):e0004061.

31. Fahal AH, Suliman SH, Hay R. Mycetoma: the spectrum of clinical presentation. Trop Med Infect Dis 2018;3(3):97.

32. Fahal A, Hassan AM, Abdel-Rahman ME, Alshambaty Y, Hashim A, Hago A, et al. A new model for management of mycetoma in the Sudan. PloS Negl Trop Dis 2014;8(10):e3271.

33. Thiyagarajan UM, Bagul A, Nicholson ML. A nodulo-cystic eumycetoma caused by Pyrenochaeta romeroi in a renal transplant recipient: a case report. J Med Case Rep 2011;5(1):460.

34. Sampaio FM, Galhardo MC, Quintella LP, Souza PR, Coelho JM, Valle AC. Eumycetoma by Madurella mycetomatis with 30 years of evolution: therapeutic challenge. An Bras Dermatol 2013;88(6):82-4.

35. Mohamed NA, Fahal AH. Mycetoma pulmonary secondaries from a gluteal eumycetoma: an unusual presentation. PloS Negl Trop Dis 2016;10(10):e0004945.

36. Ahmed A, Adelmann D, Fahal A, Verbrugh H, van Belkum A, de Hoog S. Environmental occurrence of Madurella mycetomatis, the major agent of human eumycetoma in Sudan. J Clin Microbiol 2002;40(3):1031-6.

37. de Hoog GS, Ahmed SA, Najafzadeh MJ, Sutton DA, Keisari MS, Fahal AH, et al. Phylogenetic findings suggest possible new habitat and routes of infection of human eumyctoma. PloS Negl Trop Dis 2013;7(5):e2229.

38. Fahal AH. Mycetoma: a thorn in the flesh. Trans R Soc Trop Med Hyg 2004;98(1):3-11.

39. Ameen M,Arenas R. Emerging therapeutic regimes for the management of mycetomas. Expert Opin Pharmacother 2008;9(12):2077-85.

40. van de Sande WW, Fahal AH, Goodfellow M, Welsh O, Zijlstra E. The mycetoma knowledge gap: identification of research priorities. PloS Negl Trop Dis 2014;8(3):e2667.

41. Abd ME, Fahal AH. Mycetoma revisited. Incidence of various radiographic signs. Saudi Med J 2009;30(4):529-33.

42. Bonifaz A, González-Silva A, Albrandt-Salmerón A, Del Carmen Padilla M, Saúl A, Ponce RM. Utility of helical computed tomography to evaluate the invasion of actinomycetoma; a report of 21 cases. Br J Dermatol 2008;158(4):698-704.

43. Laohawiriyakamol T, Tanutit P, Kanjanapradit K, Hongsakul K, Ehara S. The "dot-in-circle" sign in musculoskeletal mycetoma on magnetic resonance imaging and ultrasonography. SpringerPlus 2014;3(1):671.

44. Bessis S, Noussair L, Rodriguez-Nava V, Jousset C, Duran C, Beresteanu A, et al. Actinomycetoma caused by Actinomaduramexicana, a neglected entity in the Caribbean. Emerg Infect Dis 2020;26(2):376.

45. Arastehfar A, Lim W, Daneshnia F, van de Sande WW, Fahal AH, Desnos-Ollivier M, et al. Madurella real-time PCR, a novel approach for eumycetoma diagnosis. PLoS Negl Trop Dis 2020;14(1):e0007845.

46. Yan J, Deng J, Zhou CJ, Zhong BY, Hao F. Phenotypic and molecular characterization of Madurella pseudomycetomatis sp. nov., a novel opportunistic fungus possibly causing black-grain mycetoma. J Clin Microbiol 2010;48(1):251-7.

47. Ahmed A, van de Sande W, Verbrugh H, Fahal A, van Belkum A. Madurella mycetomatis strains from mycetoma lesions in sudanese patients are clonal. J Clin Microbiol 2003;41(10):4537-41.

48. Pasqualotto AC, Denning DW. New and emerging treatments for fungal infections. J Antimicrob Chemother 2008;61(Suppl 1):i19-30.

49. De Sarro A, La Camera E, Fera MT. New and investigational triazole agents for the treatment of invasive fungal infections. J Chemother 2008;20(6):661-71.

50. U.S. Food and Drug Administration (FDA). FDA Drug Safety Communication: FDA warns that prescribing of Nizoral (ketoconazole) oral tablets for unapproved uses including skin and nail infections continues; linked to patient death. Updated on 19th May 2016. Available via https://www.fda.gov/drugs/drug-safety-and-availability/ fda-drug-safety-communication-fda-warns-prescribing-nizoralketoconazole-oral-tablets-unapproved (Accessed 5th September 2020)
51. Estrada R, Chávez-López G, Estrada-Chávez G, López-Martínez R, Welsh O. Eumycetoma. Clin Dermatol 2012;30(4):389-96.

52. Kloezen W, Meis JF, Curfs-Breuker I, Fahal AH, van de Sande WW. In vitro antifungal activity of isavuconazole against Madurella mycetomatis. Antimicrob Agents Chemother 2012;56(11):6054-6.

53. Ahmed SA, Kloezen W, Duncanson F, Zijlstra EE, Sybren de Hoog $\mathrm{G}$, Fahal AH, et al. Madurella mycetomatis is highly susceptible to ravuconazole. PloS Negl Trop Dis 2014;8:e2942.

54. van de Sande WW, Fahal AH, Bakker-Woudenberg IA, van Belkum A. Madurella mycetomatis is not susceptible to the echinocandin class of antifungal agents. Antimicrob Agents Chemother 2010; 54(6):2738-40.

55. Bouchenak-Khelladi Y, Maurin O, Hurter J, Van der Bank M. The evolutionary history and biogeography of Mimosoideae (Leguminosae): an emphasis on African acacias. Mol Phylogenet Evol 2010;57(2):495-508.

56. Osman AA. Functional characteristics of gum from Acacia Nubica. Sci J Anal Chem 2016;4(6):77-83.

57. Ahmad A, Husain A, Mujeeb M, Khan SA, Najmi AK, Siddique NA, et al. A review on therapeutic potential of Nigella sativa: a miracle herb. Asian Pac J Trop Biomed 2013;3(5):337-52.

58. Siddiqui MZ. Boswelliaserrata, a potential antiinflammatory agent: an overview. Indian J Pharm Sci 2011;73(3):255.

59. Hassan BA, Glover EK, Luukkanen O, Kanninen M, Jamnadass R. Boswellia and Commiphora Species as a resource base for rural livelihood security in the Horn of Africa: a systematic review. Forests 2019;10(7):551.

60. Puvača N, Čabarkapa I, Petrović A, Bursić V, Prodanović R, Soleša $\mathrm{D}$, et al. Tea tree (Melaleuca alternifolia) and its essential oil antimicrobial, antioxidant and acaricidal effects in poultry production. Worlds Poult Sci J 2019;75(2):235-46.

61. Carson CF, Hammer KA, Riley TV. Melaleuca alternifolia (tea tree) oil: a review of antimicrobial and other medicinal properties. Clin Microbiol Rev 2006;19(1):50-62.

62. Saini RK, Sivanesan I, Keum YS. Phytochemicals of Moringa oleifera: a review of their nutritional, therapeutic and industrial significance. 3 Biotech 2016;6(2):203.

63. Sharifi-Rad M, Varoni EM, Salehi B, Sharifi-Rad J, Matthews KR, Ayatollahi SA, et al. Plants of the genus Zingiber as a source of bioactive phytochemicals: from tradition to pharmacy. Molecules 2017;22(12):2145.

64. Salehi B, Zakaria ZA, Gyawali R, Ibrahim SA, Rajkovic J, Shinwari ZK, et al. Piper species: a comprehensive review on their phytochemistry, biological activities and applications. Molecules 2019;24(7):1364.

65. Singh AK, Dhamanigi SS, Asad M. Anti-stress activity of hydroalcoholic extract of Eugenia caryophyllus buds (clove). Indian J Pharmacol 2009;41(1):28.

66. Kuete V. Other health benefits of African medicinal spices and vegetables. In: Kuete V (ed.). Medicinal spices and vegetables from Africa. 1st edition, Academic Press, Cambridge, MA, pp 329-49, 2017.

67. Bakhiet SM, Fahal AH, Musa AM, Mohamed ES, Omer RF, Ahmed $\mathrm{ES}$, et al. A holistic approach to the mycetoma management. PloS Negl Trop Dis 2018;12(5):e0006391.

\section{How to cite this article:}

Patil SM, Shirahatti PS, Jayanthi MK, Shirahatti PS, Ramu R. Role of medicinal plants in the treatment of eumycetoma: A review. J Appl Biol Biotech 2021; 9(05):176-185. 